\title{
Archéopages
}

Archéopages

Archéologie et société

$45 \mid 2017$

De la terre au pot

\section{Les édicules à pierre dressée du sanctuaire gallo- romain de Murviel-lès-Montpellier}

Gregory Vacassy

\section{(2) OpenEdition}

1 Journals

Édition électronique

URL : https://journals.openedition.org/archeopages/3579

DOI : 10.4000/archeopages.3579

ISSN : 2269-9872

Éditeur

INRAP - Institut national de recherches archéologiques préventives

Édition imprimée

Date de publication : 1 mars 2018

Pagination : 140-141

ISSN : $1622-8545$

\section{Référence électronique}

Gregory Vacassy, «Les édicules à pierre dressée du sanctuaire gallo-romain de Murviel-lès-

Montpellier », Archéopages [En ligne], 45 | 2017, mis en ligne le 01 janvier 2020, consulté le 02 juin 2021. URL : http://journals.openedition.org/archeopages/3579 ; DOl : https://doi.org/10.4000/ archeopages.3579 


\section{Édicules à pierre dressée}

Grégory Vacassy

Inrap, responsable d'opération

Site

Colline del'Yeuse

Murviel-lès-Montpellier

Hérault

Date

13 février-9 juin 2017

Superficie

$4000 \mathrm{~m}^{2}$
L’agglomération antique du

Castellas, occupée entre le début du ${ }{ }^{\mathrm{e}}$ siècle avant notre ère et le début du II ${ }^{\mathrm{e}}$ siècle de notre ère, est fouillée depuis le XIX ${ }^{\mathrm{e}}$ siècle (Raux, Thollard, 2003). Un diagnostic mené en 2016 dans un secteur péri-urbain laissait supposer la présence d'un secteur « monumental » ou tout du moins public (Vacassy, 2016). La fouille a mis en évidence un sanctuaire aux vestiges particulièrement bien conservés [ill. 1].

À un premier bâtiment construit à la charnière des $\mathrm{II}^{\mathrm{e}}$ et $\mathrm{I}^{\mathrm{er}}$ siècles avant notre ère succède un temple classique orienté vers l'est, bâti dans le courant du $\mathrm{I}^{\mathrm{er}}$ siècle avant notre ère. Dans la phase de développement maximal du lieu de culte, les édifices s'étendent autour d'une vaste place. Cette dernière est bornée, à l'ouest, par le portique d'un bâtiment longiligne composé de plusieurs pièces. Le portique, qui court aussi sur le grand côté sud de l'aire ouverte, semble démantelé dès le début du $\mathrm{I}^{\text {er }}$ siècle. Malgré la richesse du gisement, aucun élément n'a permis l'identification de la divinité à laquelle le sanctuaire était consacré. Le site a livré plusieurs dizaines de dépôts votifs encore en place. Ils se présentent sous diverses formes (amphores fichées dans le sol, édicules maçonnés, structures faites de remplois de tuiles ou de moellons) et sont regroupés en deux ensembles. Le premier est localisé immédiatement au sud du temple. Le second prend place au sud de l'emprise fouillée, très certainement après l'extension de l'aire consacrée à la divinité par la destruction du péribole du temple et le démantèlement des structures du portique.

Parmi ces dépôts, plusieurs aménagements abritent une pierre. Il en est ainsi de cinq structures constituées chacune de deux tegulae
1.Plan général simplifié du sanctuaire de Murviellès-Montpellier. 2. La pierre constitue ici le seul objet du dépôt protégé par l'aménagement en tegulae.

3. Vue de détail d'une pierre reposant sur une monnaie.

4. La pierre dressée a ici été déposée au centre d'une construction composée de moellons en remploi. 5. Cette structure en tegulae présente en son sein une pierre gravée en calcaire coquillier.

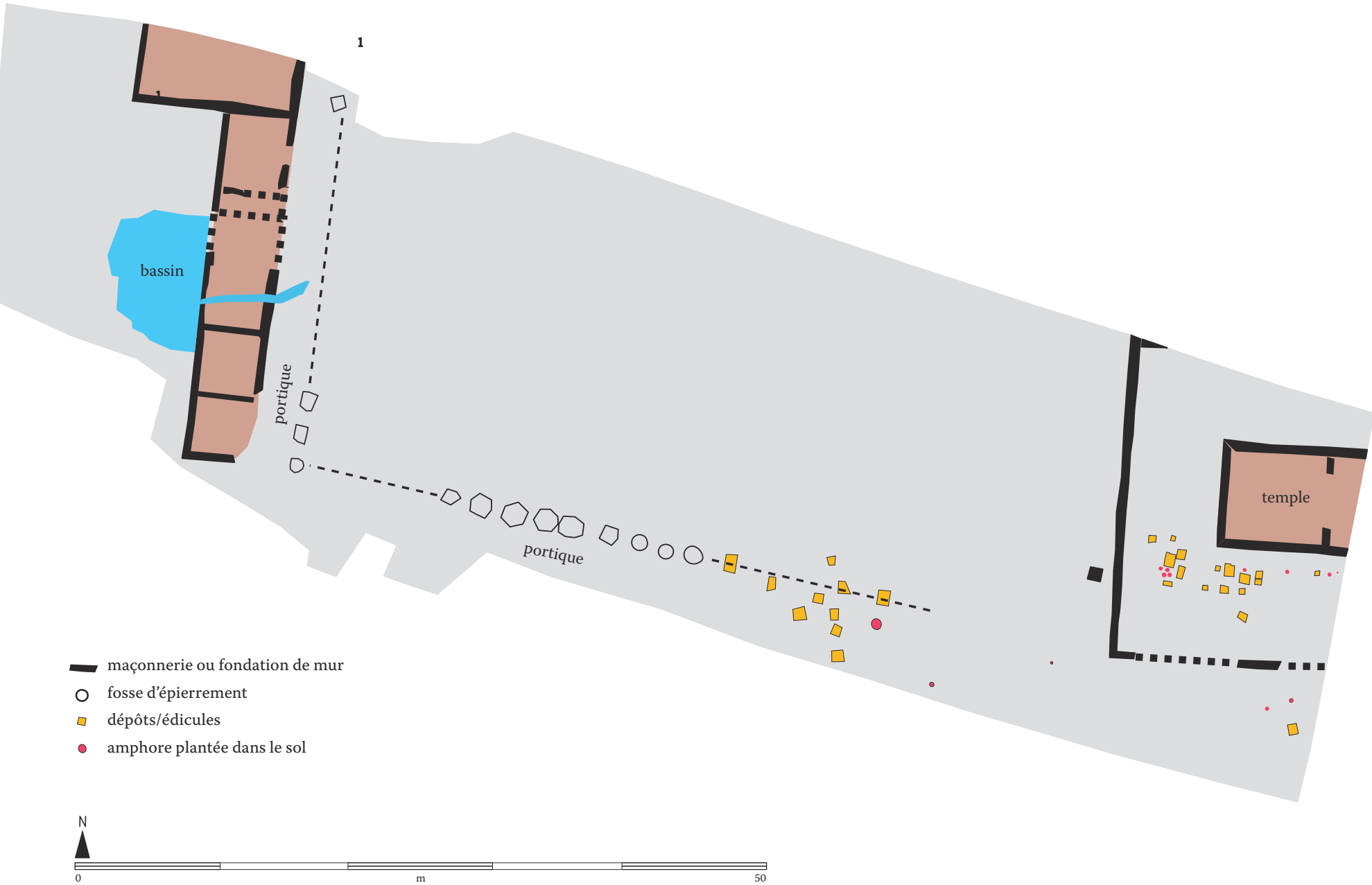


disposées en bâtière. De plan quadrangulaire, elles mesurent entre o,35 et o,40 m de côté et sont donc ouvertes sur deux faces [ill. 2]. À l'intérieur de l'aménagement, verticalement. Si ces pierres proviennent majoritairement du substrat local, on note aussi la présence de galets malgrél'absence de rivière à proximité. Leur longueur varie entre 10 et $15 \mathrm{~cm}$. Dans quatre cas, elles constituent le seul objet déposé. Dans le cinquième, cependant, la pierre repose sur une monnaie [ill. 3]. L'ensemble est toujours posé à même le sol, sans creusement préalable, et présente un aspect assez fruste.

D'autres dépôts font l'objet de plus de soin dans leur mise en œuvre. C'est en particulier le cas d'une structure constituée d'une assise de moellons en calcaire coquillier en remploi, disposés en panneresse sur $0,80 \mathrm{~m}$ de long et $0,70 \mathrm{~m}$ de large [ill. 4]. Une pierre dressée est également disposée au centre de l'espace. Une valve de cardium découverte dans l'angle sud-ouest là volontairement lors de l'accomplissement des rites. Une dernière structure, mise au jour à la pierre, oblongue, est posée pourrait également avoir été déposée proximité du temple, se distingue par la singularité de son dépôt. Trois tegulae posées verticalement, face vers l'intérieur, définissent un espace de o,40 m de côté, au sein duquel une pierre en calcaire coquillier est taillée en pyramide élancée et tronquée, d'une vingtaine de centimètres de hauteur [ill. 5]. Cette pierre présente en outre plusieurs saignées sur ses faces dont une croix centrée, gravée sur le sommet, ainsi que deux lignes parallèles courant sur les quatre faces. Enfin, une sorte de cupule est nettement visible sur la partie inférieure de la face avant. Une seconde pierre disposée de manière oblique, à l'arrière de la première, pourrait appartenir à

l'aménagement.

Bien que l'étude n'en soit qu'à ses débuts, plusieurs critères communs aux différents dépôts peuvent déjà être relevés. Outre leur aspect relativement fruste et leur mise en œuvre avec des matériaux de récupération, on peut souligner l'orientation identique de toutes ces structures, avec une ouverture disposée à l'est, à l'instar du temple proche. Enfin, la présence des pierres vise à créer une mise en scène, dont le dernier exemple cité constitue l'élément le plus manifeste. Il reste difficile, en l'état, de statuer sur l'interprétation de ces dépôts. Tout au plus peut-on avancer l'idée d'autels miniatures à bas coûts ou d'une miniaturisation de la cella proche, avec la divinité symbolisée par les cailloux. En l'absence d'inscription, on ignore à quelle pratique cultuelle rattacher ces dépôts (Van Andringa, 2002 Van Andringa, 2013): celle du votum ou celle du don?

\section{Références bibliographiques}

RAUX S., ThOLlaRd P., 2003

« L'agglomération antique du

Castellas (Murviel-lès-Montpellier, Hérault). Nouveau programme

de recherches. Premiers résultats t. $36, n^{\circ} 1$, p. 51-92.

VACASSY G., 2016, Colline de l'Yeuse Murviel-lès-Montpellier: Occitanie - Pyrénées Méditerranée, Hérault, rapport d'opération, Inrap-SRA Occitanie, 76 p. en Gaule romaine, Paris, Éditions Errance, $336 \mathrm{p}$.

VAN ANDRINGA W., 2013, «Des eśpaces et des rites : archéologie des cultes de lépoque romaine", in Schäfer A., Witteyer M. (éd.), Rituelle Deponierungen in Heiligtümern der hellenostischrömischen welt, Mainz,

Generaldrektion Kulturelles Erbe, p. 35-52. Revue archéologique de Narbonnaise,

VAN ANDRINGA W., 2002, La religion

荘
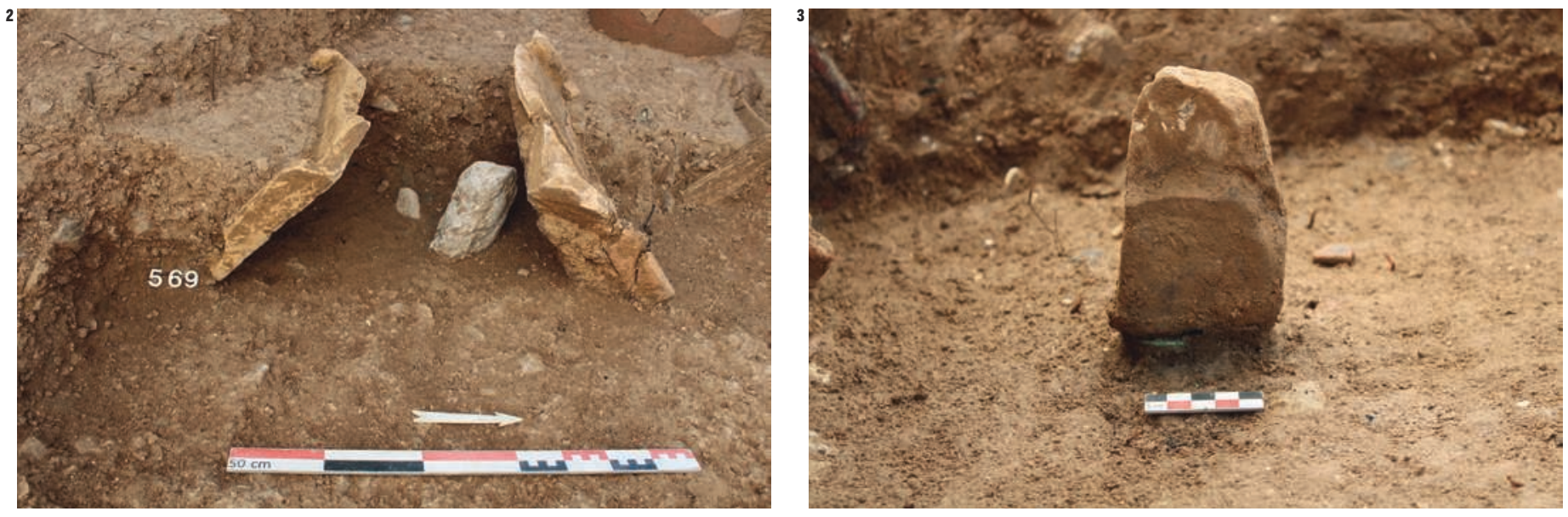

공
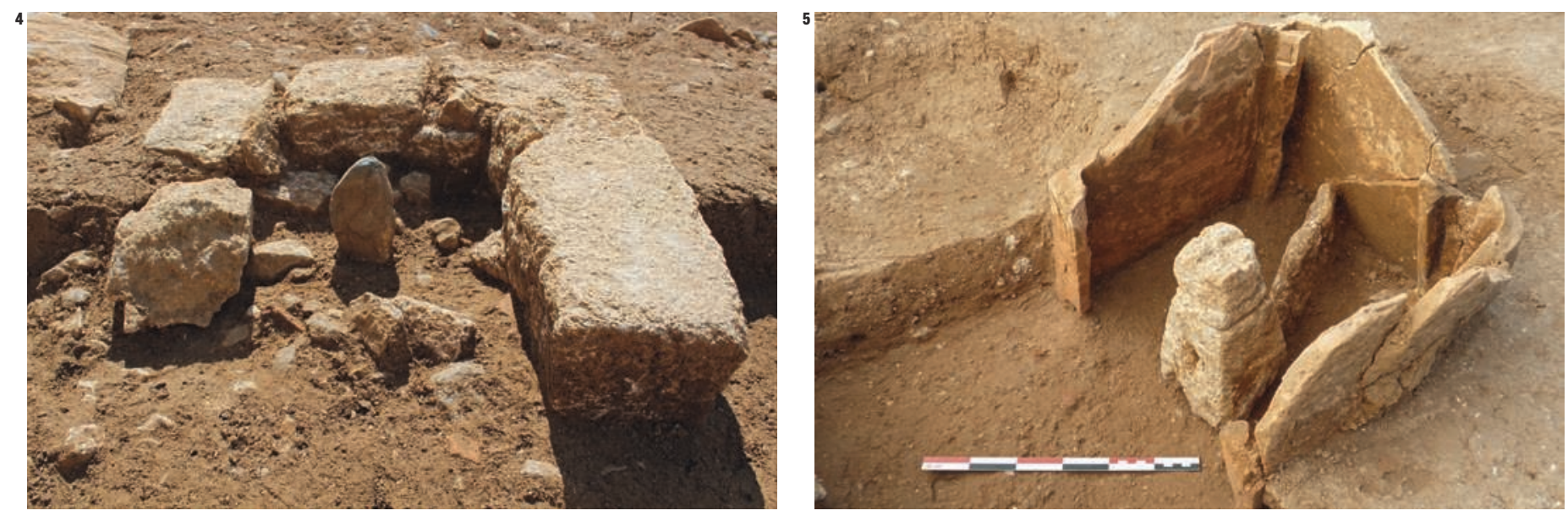